\title{
Validation of a general method for activity estimation of cyanide evolving oxidoreductases
}

\author{
Francisco Gasteazoro a , Ariane Jalila Simaan ${ }^{\mathrm{b}}$, Raunel Tinoco-Valencia ${ }^{\mathrm{c}}$, Brenda Valderrama ${ }^{\mathrm{a}, *}$ \\ ${ }^{a}$ Departamento de Medicina Molecular y Bioprocesos, Instituto de Biotecnología, Universidad Nacional Autónoma de México, Cuernavaca, Morelos 62210, Mexico \\ ${ }^{\mathrm{b}}$ Institut des Sciences Moléculaires de Marseille, Aix Marseille Université, Centrale Marseille, CNRS, iSm2, UMR 7313, 13397 Marseille, France \\ ${ }^{\mathrm{C}}$ Unidad de Escalamiento y Planta Piloto, Instituto de Biotecnología, Universidad Nacional Autónoma de México, Cuernavaca, Morelos 62210, Mexico
}

\section{A R T I C L E I N F O}

\section{Article history:}

Received 2 July 2014

Received in revised form 8 September 2014

Accepted 13 October 2014

Available online 15 November 2014

\section{Keywords:}

Biocatalysis

Enzymes

Ethylene

Gas chromatography

Liquid chromatography

\begin{abstract}
A B S T R A C T
Ethylene is a key molecule in organic synthesis currently produced by steam cracking of fossil hydrocarbons. In nature, ethylene is produced in higher plants by 1-aminocyclopropane-1-carboxylic acid oxidase (ACCO). Biocatalytic alternatives for ethylene production are still far from being competitive with traditional production plants. Furthermore, data dispersion shown in the literature adds uncertainty to the introduction of ACCO as a biocatalyst, especially when larger numbers of isoforms or mutants are to be compared. Here we propose a new method for measuring ACCO activity based on cyanide detection. Data provided here indicate that cyanide detection is more precise, more responsive, and much more stable than any other method tested for ACCO activity estimation so far. Briefly, enzymatically produced cyanide can be detected by its derivatization with naphthalene-2,3-dicarboxyaldehide (NDA) to generate 1-cyanobenz[f]isoindole (CBI), which is further detected by high-performance liquid chromatography (HPLC) coupled with a fluorescence detector. Cyanide can be detected in the range between 0.99 and 60.17 pmol, which is three orders of magnitude more sensitive than the currently used ethylene estimation method.
\end{abstract}

(c) 2014 Elsevier Inc. All rights reserved.
The transition of conventional industries toward cleaner alternatives relies on the development of suitable biocatalytic processes. Biocatalysis excels over chemical counterparts due to its inherent ability to perform reactions stereo-, enantio-, and chemospecifically. There are a number of biocatalytic reactions that have been successfully incorporated into industrial processes with the concomitant reduction of required water and energy and also in the generation of byproducts $[1,2]$. One of the many fields of the chemical industry that may be displaced by biocatalytic processes is the production of a group of small molecules that are important feedstock for the chemical industry: methanol, ammonia, aromatics, and olefins [3-5].

Ethylene, the simplest olefin, is a key molecule in organic synthesis [6]. Global ethylene production in 2011 was close to 142 million metric tons, and it is forecasted to reach 165 million metric tons by 2015, surpassing all other organic petrochemicals in production and in the amount sold [1,7]. Ethylene is used as a raw material for a great number of commercial synthetic organic chemical products (e.g., polyethylene, acetaldehyde, ethylene oxide, eth-

\footnotetext{
* Corresponding author.

E-mail address: brenda@ibt.unam.mx (B. Valderrama).
}

anol), being mainly produced by steam cracking of hydrocarbons in the petrochemical industry, a process that requires high pressure and high temperature. Although biocatalytic alternatives for ethylene production are still far from competitive with traditional production plants, they offer new opportunities in accordance with the principles of green chemistry $[2,7,8]$. Ethylene, an essential hormone for many aspects of plant life such as root development, germination, senescence, fruit ripening, and defense mechanisms [9], is naturally produced by higher plants from 1-aminocyclopropane-1-carboxylic acid (ACC), ${ }^{1}$ a metabolite of methionine [10], and the last step of its biosynthesis is catalyzed by ACC oxidase (ACCO) (Fig. 1) [11].

There is a significant amount of information regarding the sequence, structure, and catalytic mechanism of ACCO [12-17], and this enzyme arises as a natural target for further catalytic improvement by protein engineering methods. ACCO activity is usually measured following Mitchell and coworkers, where the

\footnotetext{
1 Abbreviations used: ACC, 1-aminocyclopropane-1-carboxylic acid; ACCO, ACC oxidase; DTT, dl-dithiothreitol; $\mathrm{Fe}\left(\mathrm{NH}_{4}\right)_{2}\left(\mathrm{SO}_{4}\right)_{2} \cdot 6 \mathrm{H}_{2} \mathrm{O}$, ammonium iron(II) sulfate hexahydrate; NDA, naphthalene-2,3-dicarboxyaldehyde; CBI, 1-cyanobenz[f]isoindole; EDTA, ethylenediaminetetraacetic acid; HPLC, high-performance liquid chromatography; KCN, potassium cyanide.
} 
$\int_{\mathrm{NH}_{3}}^{\mathrm{COO}^{-}}+\mathrm{O}_{2}+2 \mathrm{H}^{+}+2 \mathrm{e}^{-}$(Asc) $\underset{\mathrm{CO}_{2}\left(\mathrm{HCO}_{3}^{-}\right)}{\longrightarrow} \mathrm{CH}_{2}+\mathrm{HCN}+\mathrm{CO}_{2}+2 \mathrm{H}_{2} \mathrm{O}$

Fig.1. Reaction catalyzed by ACCO.

production of ethylene formed is determined on a gas chromatograph attached to a flame ionization detector [18]. Seldom has the determination of oxygen consumption using a Clark electrode been reported as well [19]. By using these methodologies, catalytic parameters of native enzymes from different sources have been reported with $K_{\mathrm{m}}$ values for ACCO ranging from 0.032 to $2.87 \mathrm{mM}$ [20-23]. The two orders of magnitude variation among these data may arise from differences in the purification protocol, in the reaction conditions, or in the detection uncertainty. Strong variation on the catalytic parameters is shown even for the same isoform expressed in Escherichia coli with $K_{\mathrm{m}}$ values ranging from 0.03 to $0.130 \mathrm{mM}$, whereas apparent $k_{\text {cat }}$ values ranged from 6.1 to $354 \mathrm{~min}^{-1}[24,25]$. Data dispersion shown in the literature adds uncertainty to the introduction of ACCO as a biocatalyst, especially when larger numbers of isoforms or mutants are to be compared. Therefore, it is necessary to obtain more robust and sensitive methodologies for the screening of ACCO in a protein engineering scheme.

Here we propose a new method for measuring ACCO activity based on cyanide detection. Indeed, data provided here indicate that cyanide detection is more precise, more responsive, and much more stable than any other method tested for ACCO activity estimation so far.

\section{Materials and methods}

All chemical supplies were of reagent-grade purity and purchased from Sigma-Aldrich unless otherwise stated. Restriction enzymes and ligase were purchased from New England Biolabs, and pET32a(+) was purchased from Novagen.

All experiments presented in this article were performed with the same enzyme batch and are representatives of at least three rounds of experiments performed with the same number of pure samples.

\section{Vector construction for ACCO expression}

ACCO was subcloned in pET32a(+). The vector was first digested with NdeI and BamHI and then purified with a GeneJet Gel Extraction Kit from Fermentas. The ACCO gene contained in pET-21a was restricted with the same pair of enzymes; the 945-bp fragment liberated was purified from gel. The ACCO fragment was then ligated into the previously restricted pET32a(+) and transformed into E. coli DH5 $\alpha$ cells. A number of colonies were picked and screened for the ACCO gene by restriction, and the ACCO gene was further confirmed by sequencing. Expression of ACCO was placed under the control of a T7 promoter. The vector also includes the E. coli ampicillin resistance gene. The expression construction is referred to as pET32ACCO. This plasmid was then transformed into E. coli BL21 for protein expression.

\section{ACCO expression}

A 0.25-L LB broth inoculum flask (supplemented with $20 \mu \mathrm{g} \mathrm{ml} \mathrm{m}^{-1}$ ampicillin) was grown at $37^{\circ} \mathrm{C}$ in a shaker for $12 \mathrm{~h}$. The inoculum was added to a 10 -L fermenter operated at $37^{\circ} \mathrm{C}$, $300 \mathrm{rpm}$, and $0.33 \mathrm{vvm}$ to an $A_{600}$ between 0.4 and 0.6 , at which time isopropyl- $\beta$-D-thiogalactopyranoside (IPTG) was added to a final concentration of $0.5 \mathrm{mM}$. Growth was continued at $28^{\circ} \mathrm{C}$ for an additional $3 \mathrm{~h}$, and cells and supernatant were separated by centrifugation.

\section{Purification of ACCO}

Cells were resuspended in $25 \mathrm{mM}$ Hepes (pH 8.0), $50 \mathrm{mM} \mathrm{NaCl}$, $5 \mathrm{mM}$ dl-dithiothreitol (DTT), 10\% glycerol, DNase I (10 U/ml), lysozyme $\left(10 \mu \mathrm{g} \mathrm{ml}^{-1}\right)$, and protease inhibitor Complete EDTA-Free (Roche). Three ultrasonic pulses were used to lysate the resuspended cells. The lysate was centrifuged at $13,000 \mathrm{rpm}$ at $4{ }^{\circ} \mathrm{C}$ for $30 \mathrm{~min}$. The supernatant was precipitated with ammonium sulfate to a saturation concentration of $60 \%$, this mixture was again centrifuged at $13,000 \mathrm{rpm}$ at $4{ }^{\circ} \mathrm{C}$, and the supernatant was collected. Ammonium sulfate was added to $80 \%$ saturation, and the mixture was centrifuged with the same conditions. The pellet was recovered and resuspended in $25 \mathrm{mM}$ Hepes ( $\mathrm{pH}$ 8.0) and $3 \mathrm{M}$ ammonium sulfate and loaded onto Macro-Prep t-Butyl Resin (Bio-Rad) equilibrated with buffer ( $25 \mathrm{mM}$ Hepes, $\mathrm{pH} 8.0$ ) and $3 \mathrm{M}$ ammonium sulfate. The column was washed with the same buffer. ACCO was eluted from the column in a linear gradient (3-0 M ammonium sulfate in buffer ( $25 \mathrm{mM}$ Hepes).

Fractions containing ACCO were dialyzed in $25 \mathrm{mM}$ Hepes $(\mathrm{pH}$ 8.0), $5 \mathrm{mM}$ DTT, and 10\% glycerol to further load onto Q-Sepharose Fast-Flow (Sigma) equilibrated with the same buffer. The column was washed with this buffer, and the retained fractions were eluted with a 0 - to $0.5-\mathrm{M} \mathrm{NaCl}$ linear gradient. The fractions containing ACCO were dialyzed in $25 \mathrm{mM}$ Hepes ( $\mathrm{pH} 7.2$ ) to further concentration in a Centricon 10K MWCO (molecular weight cutoff) device (Millipore). In all of the purification steps, ACCO fractions were selected as determined by sodium dodecyl sulfate polyacrylamide gel electrophoresis (SDS-PAGE). Gels were prestained by adding $0.5 \%$ of 2,2,2-trichloroethanol into gel mixture [26], and gel images were obtained with a Gel Doc EZ System (Bio-Rad) using the stain-free tray filter. Protein concentration was determined by Bradford assay using bovine serum albumin (BSA) as a standard.

\section{Iron quantification}

ACCO preparation iron content was determined by a modification of the Hennessy and coworkers methodology [27]. To quantify iron content in the enzymatic preparation, $250 \mu \mathrm{l}$ of ACCO mixture was denatured by the addition of $20 \mu \mathrm{l}$ of $\mathrm{HCL}(1 \mathrm{M})$, and this denatured solution was instantly neutralized with $20 \mu \mathrm{l}$ of $\mathrm{NaOH}(1 \mathrm{M})$. The obtained mixture was centrifuged at $10,000 \mathrm{rpm}$ for $5 \mathrm{~min}$. The supernatant was reduced with $200 \mu \mathrm{l}$ of a solution of ascorbic acid $(1 \mathrm{M})$ and completed to a 1-ml final volume of buffer acetate $(\mathrm{pH}$ 4.5 ) with ferene $S$ (final concentration of $0.638 \mathrm{mM}$ ). The mixture was incubated for $5 \mathrm{~min}$ at room temperature to allow color development. Absorbance of the sample was measured at $593 \mathrm{~nm}\left(\lambda_{593}=34,500 \mathrm{~L} \mathrm{~cm}^{-1} \mathrm{~mol}^{-1}\right)$ using a Thermo Scientific spectrophotometer.

\section{ACCO activity assays}

ACCO activity was measured using ACC, ammonium iron(II) sulfate hexahydrate $\left[\mathrm{Fe}\left(\mathrm{NH}_{4}\right)_{2}\left(\mathrm{SO}_{4}\right)_{2} \cdot 6 \mathrm{H}_{2} \mathrm{O}\right], \mathrm{NaHCO}_{3}$, and L-ascorbic acid [25].

Ethylene determination was performed at room temperature in $1.7 \mathrm{ml}$ of hermetically sealed vials. The total assay volume was $200 \mu \mathrm{l}$ and contained $100 \mathrm{mM}$ Hepes buffer at $\mathrm{pH} 7.2,102.8 \mu \mathrm{g}$ of ACCO, $18 \mathrm{mM} \mathrm{NaHCO}, 8 \mathrm{mM}$ L-ascorbic acid, $80 \mu \mathrm{M} \mathrm{Fe}\left(\mathrm{NH}_{4}\right)_{2}$ $\left(\mathrm{SO}_{4}\right)_{2} \cdot 6 \mathrm{H}_{2} \mathrm{O}$, and $5 \mathrm{mM}$ ACC. After $2 \mathrm{~min}$ of reaction, $250 \mu \mathrm{l}$ of headspace gas was removed using a gas-tight syringe and ethylene production was quantified by gas chromatography. Measurements 
were performed by varying the concentration of ACC while maintaining the concentration of the other substrates. Nonlinear curve fitting to the Michaelis-Menten equation was performed using SigmaPlot 11.0 to determine kinetic parameters. Gas chromatography measurements were performed with an Agilent 6890N gas chromatograph equipped with a fused silica capillary column Gas-Pro (J \& W, $30 \mathrm{~m} \times 0.32 \mathrm{~mm}$ ) and a flame ionization detector. The following conditions were used: He (99.999\%) as a carrier gas $\left(1.4 \mathrm{ml} \mathrm{min}^{-1}\right)$, in split mode $(20: 1), T_{\text {injector }}=250, T_{\text {oven }}=90$, and $T_{\text {detector }}=260$. Ethylene was quantified versus an external standard of ethylene (99.99\%) from Sigma.

Oxygen consumption was measured using an Oxygraph device (Hansatech Instrument, King's Lyan, UK) equipped with an oxygen electrode, a gas-tight cap, and a Teflon-coated stirrer bar. The Oxygraph was controlled by and configured from a personal computer, via custom software supplied by the manufacturer, which also recorded oxygen concentration in the chamber over time. Instrument calibration was performed according to the manufacturer's instructions using the same buffer for the enzymatic reactions and $99.5 \%$ nitrogen. Temperature was maintained at $19{ }^{\circ} \mathrm{C}$. Standard reaction mixture $(1 \mathrm{ml})$ contained $100 \mathrm{mM}$ Hepes $(\mathrm{pH} 7.2)$, $205.6 \mu \mathrm{g}$ of ACCO, $18 \mathrm{mM} \mathrm{NaHCO} 3,8 \mathrm{mM}$ L-ascorbic acid, and $5 \mathrm{mM}$ ACC. Reconstituted ACCO with $0.74 \mathrm{Fe}\left(\mathrm{NH}_{4}\right)_{2}\left(\mathrm{SO}_{4}\right)_{2} \cdot 6 \mathrm{H}_{2} \mathrm{O}$ molar excess was used to start the reactions. All rates were calculated subtracting background oxygen consumption [19]. Measurements were performed by varying the concentration of ACC while maintaining the concentration of the other substrates. Nonlinear curve fitting to the Michaelis-Menten equation was performed using SigmaPlot 11.0 to determine kinetic parameters.

Cyanide was quantified after derivatization by a modification of the method of Driesener and coworkers [28], in which the cyanide anion reacts with naphthalene-2,3-dicarboxyaldehyde (NDA) and a primary amine, generating the fluorescent 1-cyanobenz[f]isoindole (CBI) derivative (Fig. 2) [29]. Standard reaction mixture $(100 \mu \mathrm{l})$ contained $100 \mathrm{mM}$ Hepes ( $\mathrm{pH} 7.2$ ), $1.29 \mu \mathrm{g}$ of ACCO, $18 \mathrm{mM}$ $\mathrm{NaHCO}_{3}, 8 \mathrm{mM}$ L-ascorbic acid, $80 \mu \mathrm{M} \mathrm{Fe}\left(\mathrm{NH}_{4}\right)_{2}\left(\mathrm{SO}_{4}\right)_{2} \cdot 6 \mathrm{H}_{2} \mathrm{O}$, and $5 \mathrm{mM}$ ACC. Initial velocities were measured at $18^{\circ} \mathrm{C}$. Reactions were ended with the addition of $50 \mathrm{mM}$ ethylenediaminetetraacetic acid (EDTA, pH 8.0). All rates were calculated subtracting background cyanide production. For derivatization, 3.44 mM NDA in methanol and $1.9 \mathrm{mM}$ ACC in buffer (100 mM Hepes, $\mathrm{pH}$ 7.2) were added to the ACCO reaction. Derivatization proceeded for $5 \mathrm{~min}$ at $95^{\circ} \mathrm{C}$. After derivatization, fluorescence was measured by

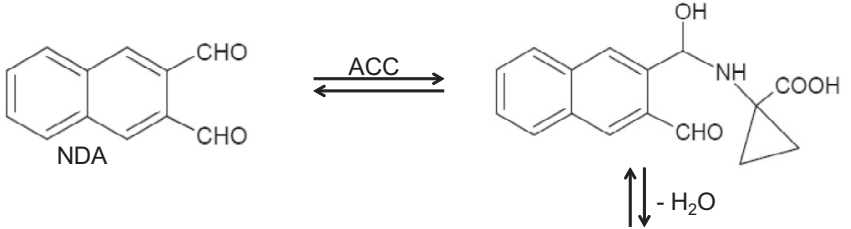<smiles>N#CC(NC1(C(=O)O)CC1)c1cc2ccccc2cc1/C=[NH+]/C1(C(=O)O)CC1</smiles><smiles>N#Cc1c2cc3ccccc3cc2cn1C1(C(=O)O)CC1</smiles>

Fig.2. Scheme of cyanide derivatization with NDA and ACC. (Modified from Carlson et al. [29].)

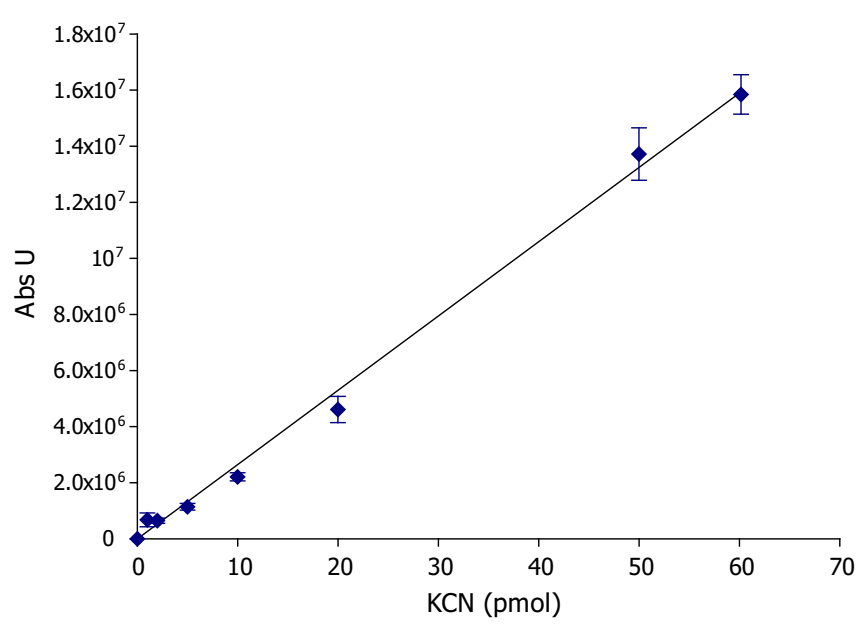

Fig.3. Calibration plot of KCN derivatized with NDA and ACC. Lower and higher dots on plot are detection and quantification limits for CBI under working conditions.

high-performance liquid chromatography (HPLC). Chromatographic separation was achieved by injecting $20 \mu \mathrm{l}$ of derivatized supernatant into a Hypersil C18 ZORBAX Eclipse reverse phase column $(4.6 \times 100 \mathrm{~mm})$. The chromatography buffers were $2 \mathrm{mM}$ ammonium formate ( $\mathrm{pH}$ 3.0) (solvent A) and methanol (solvent B), and the initial mobile phase contained $20 \%$ solvent B for $5 \mathrm{~min}$, followed by a gradient to $65 \%$ solvent B over $20 \mathrm{~min}$ and then $100 \%$ solvent B over 2 min, where it was held isocratically for $10 \mathrm{~min}$. The CBI derivative eluted with a retention time of approximately $27 \mathrm{~min}$ and was detected fluorometrically by the signal emitted at $\lambda_{\mathrm{ex}}=418 \mathrm{~nm}$ and $\lambda_{\mathrm{em}}=454 \mathrm{~nm}$. To establish a cyanide calibration plot, potassium cyanide (KCN) standards (1$99 \mathrm{pmol}$ ) in $100 \mathrm{mM}$ Hepes ( $\mathrm{pH} 7.2$ ) were prepared and subjected to the same conditions as ACCO assays (Fig. 3).

\section{Results and discussion}

The tomato ACCO gene codified in pET-21a has been widely used for the heterologous expression of the enzyme in E. coli $[12,17,24,30]$; however, the resulting ACCO was lower than expected based on the literature and on our experience [31]. To increase the yield, the tomato ACCO gene was subcloned into pET32a $(+)$, acquiring the expected ability to produce three times more protein than with the previous construction, which is crucial for an optimal purification methodology. The current protocol used for ACCO purification generates enough material for protein characterization; however, we identified two weaknesses: (i) the preparation obtained was not high purity, and this will certainly affect the determination of the catalytic parameters, and (ii) the Fe naturally present on the active site of the enzyme is removed as a result of the EDTA addition at the protein extraction stage of the purification [25]. Because ACCO catalysis is Fe dependent, this ion must be provided again in the reaction medium, with the unavoidable generation of reactive oxygen species.

To relieve these restrictions, we developed an EDTA-free protein purification protocol that allowed fast purification from large culture volumes, important to avoid excessive handling procedures that can damage the protein [19], and with higher yields of protein (10 $\mathrm{mg} / \mathrm{L}$ of $\sim 98 \%$ relative purity) (Fig. 4). We obtained a highly active protein preparation with $16.5 \mathrm{~mol}$ ethylene/mol enzyme/ min [24], which is in the activity range described by using the methodology previously reported by Thrower and coworkers [19]. The natural Fe content of $35 \%$ in ACCO was conserved because purification was performed without EDTA. High protein yield with 


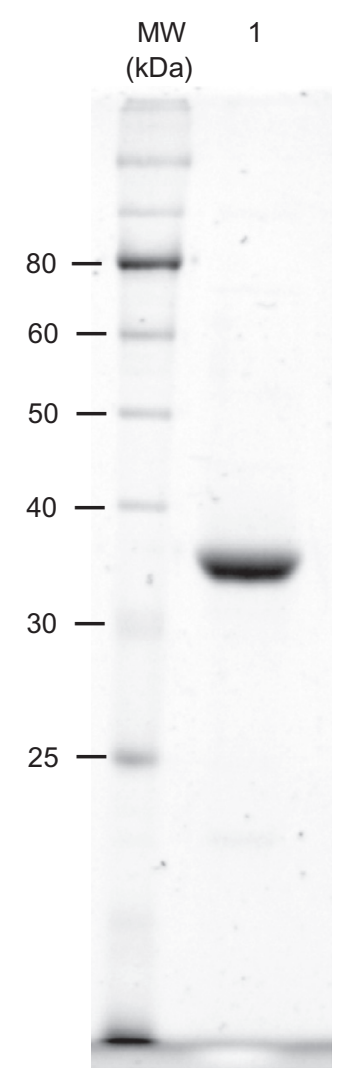

Fig.4. Denaturing polyacrylamide gel electrophoresis (PAGE) revealed by 2,2,2trichloroethanol molecular weight ladder (MW) and ACCO preparation after EDTAfree purification protocol (lane 1).

good specific activity indicated that no deactivation took place during purification and, therefore, that no EDTA addition is required throughout the process.

The enzyme preparation was characterized using the following methods: production of ethylene, oxygen consumption, and cyanide production. Ethylene production was measured as reported elsewhere, varying ACC while keeping all other substrate concentrations fixed at saturation [25]. Ethylene was quantified using a calibration plot ranging from 0.81 to $801 \mathrm{nmol}$ that fits into a linear equation. Steady-state kinetics of ethylene production was determined using velocity rates for ethylene production under initial velocity conditions. Ethylene production rates were analyzed using the Michaelis-Menten model, and kinetic parameters obtained were $K_{\mathrm{m}}=0.17 \pm 0.07 \mathrm{mM}$ and $k_{\text {cat }}=17.45 \pm 1.41 \mathrm{~min}^{-1}\left(R^{2}=0.85\right)$.

For oxygen consumption, we followed the methodology described by Thrower and coworkers [19], and the enzymatic reaction was started with protein previously charged with 0.74 molar excess of ferrous iron to avoid oxygen consumption in the electrode due to free iron in the reaction medium. The reaction was followed for several minutes, and activity rates were measured in accordance with steady-state kinetics. Oxygen consumption rates were subjected to the same treatment as ethylene production data, and kinetic parameters obtained were $K_{\mathrm{m}}=0.60 \pm 0.23 \mathrm{mM}$ and $k_{\text {cat }}=3.98 \pm 0.46 \mathrm{~min}^{-1}$. Although these data sets presented significant dispersion, they satisfactorily fulfilled the Michaelis-Menten model $\left(R^{2}=0.84\right)$.

All of our results but $k_{\text {cat }}$ obtained with oxygen consumption approached those found in the literature for the same ACCO isoform, where $K_{\mathrm{m}}$ values ranged from 0.03 to $0.15 \mathrm{mM}$ and apparent $k_{\text {cat }}$ ranged from 11.3 to $354 \mathrm{~min}^{-1}$ [24,25]. It is important to note that there is at least one order of magnitude difference between reports. When we compare the catalytic parameters reported here, we find that $K_{\mathrm{m}}$ is nearly 4 times larger and $k_{\text {cat }}$ and approximately 4 times smaller between oxygen consumption and ethylene production. These differences may arise from physical or chemical differences between methods. For instance, ethylene detection is dependent on accumulation of the product in vials, on saturation of the liquid phase of the reaction, and on further manipulation of the sample until its detection in the gas chromatograph [32,33]. Therefore, this assay does not necessarily provide a direct value for concentration of ethylene but does so for the rate at which the ethylene equilibrates between the reaction mixture and the enclosing air phase [34]. In addition, the sensitivity of this method is lower, with a confidence interval between 210 and $420 \mathrm{pmol}$ ethylene $\mathrm{ml}^{-1}$. On the other side, precision of oxygen measurements using Clark electrode deviations have been reported to depend on different aspects such as membrane damage [35], deterioration of the electrode by deposition of $\mathrm{AgCl}$ in the silver anode [36], and the occurrence of nonenzymatic oxygen consumption exacerbated by ascorbic acid [19,37-40]. In addition, oxygen detection is highly dependent on the temperature and is a time-consuming method not suitable for the analysis of a large number of samples. Finally, it is not a sensitive method $\left(0.01 \times 10^{6}\right.$ to $8.4 \times 10^{6}$ pmol oxygen $\left.\mathrm{min}^{-1}\right)$ [41], demanding large amounts of ACCO to detect a significant signal.

Taking into account the drawbacks of the two methodologies available for ACCO activity assays, we propose a methodology based on the method of Driesener and coworkers [28,42]. Briefly, enzymatically produced cyanide can be detected by its derivatization with NDA to generate CBI, which is further detected by HPLC coupled with a fluorescence detector. Modifications needed to be developed for the use of ACC as primary amine instead of taurine. When the enzymatic activity was tested in the presence of taurine and ACC, the chromatogram presented a complex pattern due to different $C B I$ isoforms, one for each R-amine group present. In the chromatograms with and without taurine (Fig. 5A and B, respectively), compound identification was assigned by systematic exclusion of one or more reactants. The retention time for $\mathrm{CBI}$ formed with the R-amine group of ACC presents a retention time close to $26 \mathrm{~min}$ and is clearly distinguishable from that formed with taurine that appears at $22 \mathrm{~min}$. The retention time shift observed among chromatograms may be due to the different viscosity of individual samples. ACC was added to the reaction in excess, as were the substrates for ACCO activity reaction and for HCN detection. Besides, controls where all reagents present at the ACCO reaction mixture were added individually or in different combinations were run to ensure that none of them interfered with cyanide measurement. It is important to note that complete derivatization required $5 \mathrm{~min}$ at $95^{\circ} \mathrm{C}$ and $\mathrm{pH}$ control with Hepes $(100 \mathrm{mM}, \mathrm{pH} 7.2)[43,44]$. Once the derivatization methodology was settled, a calibration plot was established with a KCN standard in the range between 0.99 and $60.17 \mathrm{pmol}$ that fitted into a linear equation, making this method three orders of magnitude more sensitive than ethylene estimation [42] and all other colorimetric cyanide determination methodologies reported to date $[45,46]$. A highly sensitive methodology allows a better quantification of the released product; the estimation is performed at the liquid phase, striving against the ethylene assay weaknesses described previously.

Different ACCO concentrations were tested to confirm the linear character of the cyanide production rate (Fig. 6). To obtain steadystate kinetic values for cyanide production, experiments were performed varying ACC content while keeping all other substrates at saturation levels. For each ACC concentration, reactions were allowed to proceed for $2 \mathrm{~min}$ at $19{ }^{\circ} \mathrm{C}$, samples were taken every $30 \mathrm{~s}$ for derivatization, and initial velocity was determined by feeding data into a linear equation fitting (Fig. 7). Nonlinear curve 

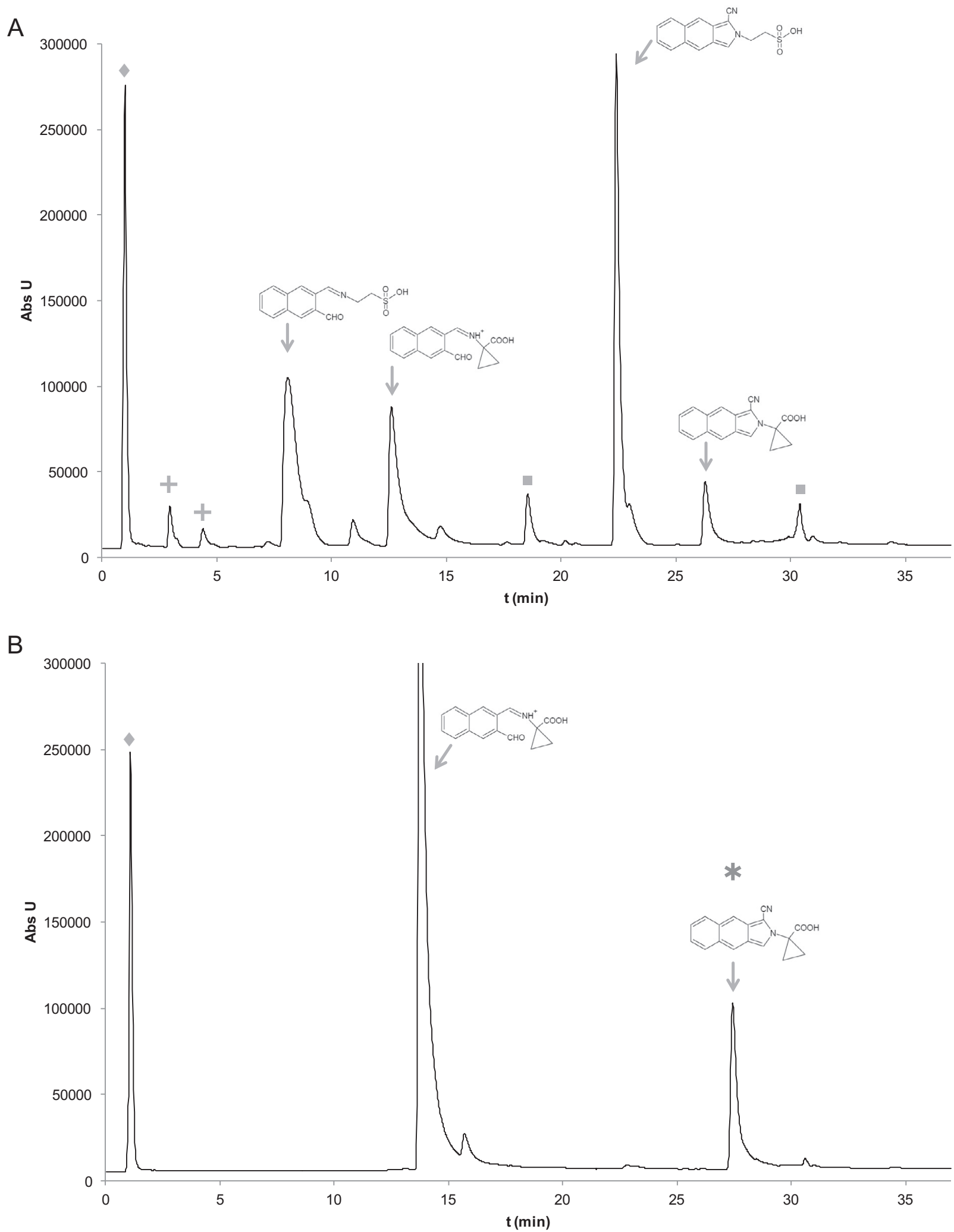

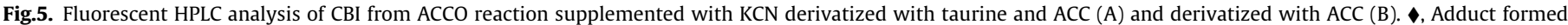
when the reaction mixture is complete; +, taurine adducts; $\mathbf{\square}$, adducts formed when ACCO and taurine present in the reaction; $*$, $\mathrm{CBI}-\mathrm{ACC}$ adduct.

fitting into the Michaelis-Menten model was performed to initial velocities using the data presented in Fig. 8, where $K_{\mathrm{m}}=0.88 \pm 0.14 \mathrm{mM}$ and $k_{\text {cat }}=10.52 \pm 0.55 \mathrm{~min}^{-1}\left(R^{2}=0.97\right)$ values were obtained.
When we compared these kinetic parameters with those obtained in other experiments, we found that $K_{\mathrm{m}}$ was similar to that obtained with the oxygen consumption methodology; on the other hand, $k_{\text {cat }}$ resembled that obtained with ethylene production 


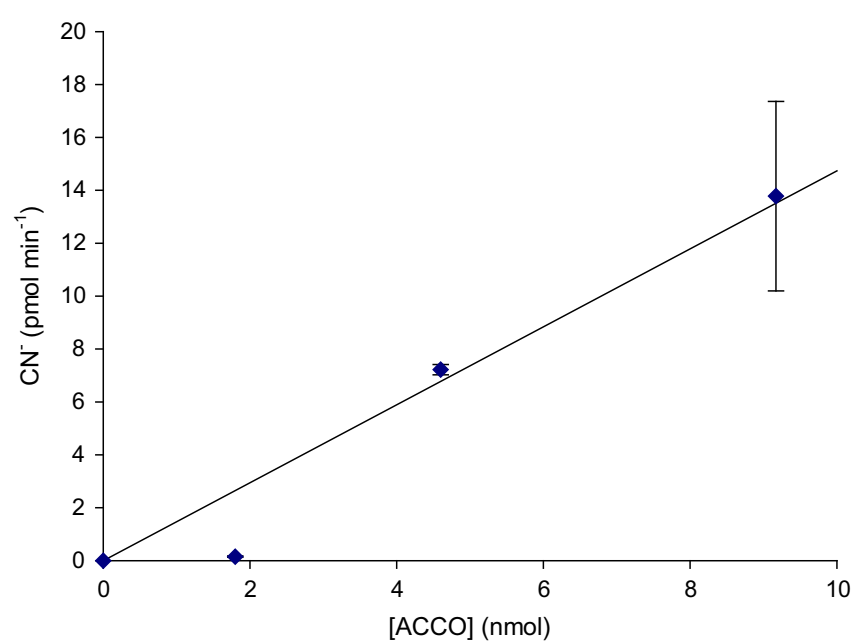

Fig.6. Cyanide $(\mathrm{CN})$ production rate at different ACCO concentrations. Data were fitted to an exponential equation $\left(R^{2}=0.94\right)$.

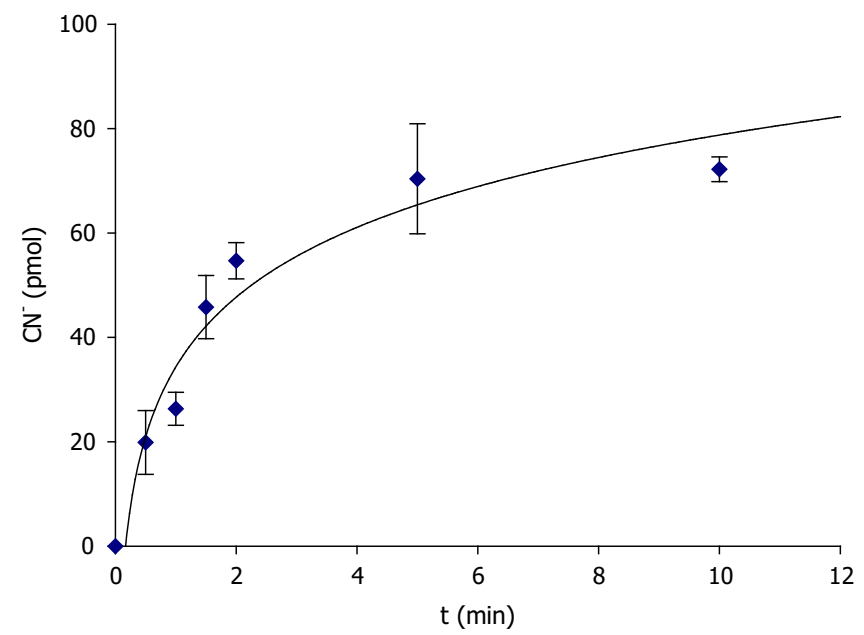

Fig.7. Time course of the ACCO reaction at substrate excess (ACC, $5 \mathrm{mM}$ ). As described in the text, the linear range was established during the first 2 min of enzyme activity. Background cyanide $(\mathrm{CN})$ generation in the absence of enzyme remained less than 5 pmol during all of the experiments. Data were fitted to an exponential equation $\left(R^{2}=0.95\right)$.

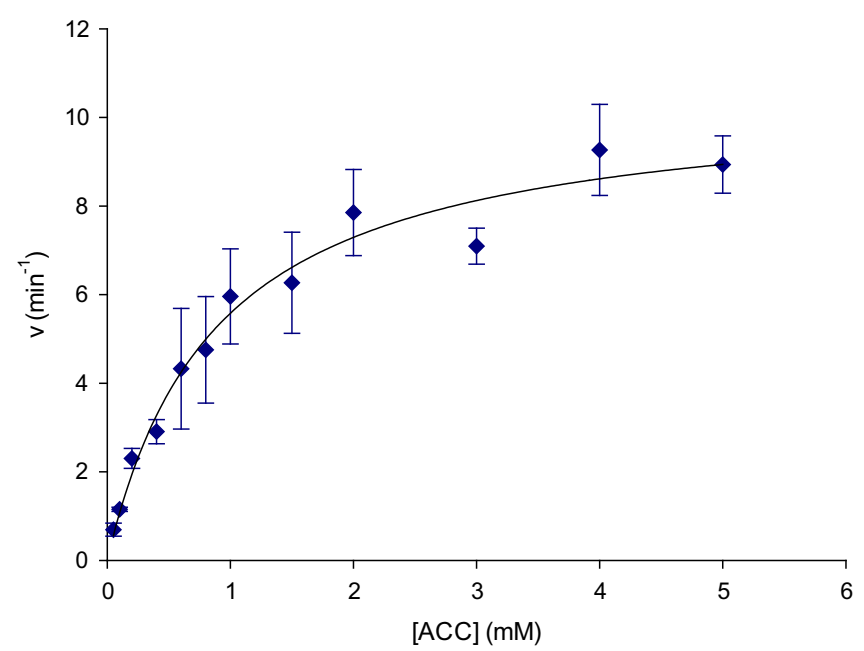

Fig.8. Michaelis-Menten fitting for the initial velocities determined for the ACCO activity measure by cyanide production.
Table 1

Comparison of kinetic parameters among experiments.

\begin{tabular}{llrl}
\hline Activity measurement & $K_{\mathrm{m}}(\mathrm{mM})$ & $k_{\text {cat }}\left(\mathrm{min}^{-1}\right)$ & $R^{2}$ \\
\hline Cyanide production & $0.88 \pm 0.14$ & $10.52 \pm 0.55$ & 0.97 \\
Ethylene production & $0.17 \pm 0.07$ & $17.45 \pm 1.41$ & 0.85 \\
Oxygen consumption & $0.60 \pm 0.23$ & $3.98 \pm 0.46$ & 0.84 \\
\hline
\end{tabular}

analysis (Table 1). Regarding the disparity in $K_{\mathrm{m}}$ value, we suggest that it is due to differences in the reaction temperature for ethylene production, although perhaps not by stabilization of the enzyme-substrate complex. Regarding the lower $k_{\text {cat }}$ value obtained by oxygen consumption, it is relevant to note that this measurement is obscured by the simultaneous occurrence of at least three different reactions in the vessel-enzymatic, Fenton, and electrode consumption-with most of the oxygen in the reaction depleted by side reactions before activity measurement.

Ethylene determination is further hampered by loss of the molecule through seals when stored in vessels and during handling. Our data suggest that the cyanide method is more precise, more responsive, and more stable than other methods tested here for estimating ACCO activity, looming as a robust methodology for activity estimation not only for ACCO but also for other cyanide evolving oxidoreductases. After the enzymatic reaction was stopped by EDTA addition, cyanide content was stable for up to 40 min of incubation at $19{ }^{\circ} \mathrm{C}$ before derivatization. Once derivatized, CBI content is stable for up to $1 \mathrm{~h}$ at room temperature.

Early reports of cyanide identification in ACCO reaction dealt with stoichiometric determinations [47]. In accordance, we found that similar amounts of products, independently measured, were released for the ACCO reaction: $17.44 \pm 1.84$ pmol cyanide/pmo$1 \mathrm{ACCO} / \mathrm{min}$ and $16.53 \pm 2.87 \mathrm{pmol}$ ethylene $/ \mathrm{pmol} \mathrm{ACCO} / \mathrm{min}$ were formed.

\section{Acknowledgments}

This project was funded by SEP-Conacyt 128156 and DGAPA IN-213010 grants. We recognize the technical support of Guadalupe Paredes Valdés, Georgina Hernández Montes, and Gloria Vázquez Castro.

\section{References}

[1] J.A. Kent (Ed.), Kent and Riegel's Handbook of Industrial Chemistry and Biotechnology, Springer, New York, 2007.

[2] E. Scott, F. Peter, J. Sanders, Biomass in the manufacture of industrial products: the use of proteins and amino acids, Appl. Microbiol. Biotechnol. 75 (2007) $751-762$.

[3] J.A. Chemier, Z.L. Fowler, M.A. Koffas, E. Leonard, Trends in microbial synthesis of natural products and biofuels, Adv. Enzymol. Relat. Areas Mol. Biol. 76 (2009) 151-217.

[4] A.-P. Zeng, H. Biebl, Bulk chemicals from biotechnology: the case of 1,3propanediol production and the new trends, in: K. Schüger, A.-P. Zeng, J.G. Aunins, A. Bader, W. Bell, H. Biebl (Eds.), Tools and Applications of Biochemical Engineering Science, Springer, Berlin, 2002.

[5] V.J. Lay, A.G. Prescott, P.G. Thomas, P. John, Heterologous expression and sitedirected mutagenesis of the 1-aminocyclopropane-1-carboxylate oxidase from kiwi fruit, Eur. J. Biochem. 242 (1996) 228-234.

[6] H.M. Torres Galvis, K.P. de Jong, Catalysts for production of lower olefins from synthesis gas: a review, ACS Catal. 3 (2013) 2130-2149.

[7] C. Eckert, W. Xu, W. Xiong, S. Lynch, J. Ungerer, L. Tao, R. Gill, P.C. Maness, J. Yu, Ethylene-forming enzyme and bioethylene production, Biotechnol. Biofuels 7 (2014) 33.

[8] N. Johansson, P. Quehl, J. Norbeck, C. Larsson, Identification of factors for improved ethylene production via the ethylene forming enzyme in chemostat cultures of Saccharomyces cerevisiae, Microb. Cell Fact. 12 (2013) 89.

[9] A.B. Bleecker, H. Kende, Ethylene: a gaseous signal molecule in plants, Annu. Rev. Cell Dev. Biol. 16 (2000) 1-18.

[10] D.O. Adams, S.F. Yang, Ethylene biosynthesis: identification of 1aminocyclopropane-1-carboxylic acid as an intermediate in the conversion of methionine to ethylene, Proc. Natl. Acad. Sci. U.S.A. 76 (1979) 170-174. 
[11] M. Costas, M.P. Mehn, M.P. Jensen, L. Que Jr., Dioxygen activation at mononuclear nonheme iron active sites: enzymes, models, and intermediates, Chem. Rev. 104 (2004) 939-986.

[12] A.M. Rocklin, K. Kato, H.W. Liu, L. Que Jr., J.D. Lipscomb, Mechanistic studies of 1-aminocyclopropane-1-carboxylic acid oxidase: single turnover reaction, J. Biol. Inorg. Chem. 9 (2004) 171-182.

[13] L.M. Mirica, J.P. Klinman, The nature of $\mathrm{O}_{2}$ activation by the ethylene-forming enzyme 1-aminocyclopropane-1-carboxylic acid oxidase, Proc. Natl. Acad. Sci. U.S.A. 105 (2008) 1814-1819.

[14] A. Bassan, T. Borowski, C.J. Schofield, P.E. Siegbahn, Ethylene biosynthesis by 1aminocyclopropane-1-carboxylic acid oxidase: a DFT study, Chemistry 12 (2006) 8835-8846.

[15] Z. Zhang, J.S. Ren, I.J. Clifton, C.J. Schofield, Crystal structure and mechanistic implications of 1-aminocyclopropane-1-carboxylic acid oxidase: the ethyleneforming enzyme, Chem. Biol. 11 (2004) 1383-1394.

[16] J.N. Barlow, Z. Zhang, P. John, J.E. Baldwin, C.J. Schofield, Inactivation of 1aminocyclopropane-1-carboxylate oxidase involves oxidative modifications, Biochemistry 36 (1997) 3563-3569.

[17] Z. Zhang, J.N. Barlow, J.E. Baldwin, C.J. Schofield, Metal-catalyzed oxidation and mutagenesis studies on the iron(II) binding site of 1-aminocyclopropane-1carboxylate oxidase, Biochemistry 36 (1997) 15999-16007.

[18] T. Mitchell, A.J.R. Porter, P. John, Authentic activity of the ethylene-forming enzyme observed in membranes obtained from kiwifruit (Actinidia deliciosa), New Phytol. 109 (1988) 313-319.

[19] J.S. Thrower, R. Blalock III, J.P. Klinman, Steady-state kinetics of substrate binding and iron release in tomato ACC oxidase, Biochemistry 40 (2001) 9717-9724.

[20] D.J. McGarvey, R.E. Christoffersen, Characterization and kinetic parameters of ethylene-forming enzyme from avocado fruit, J. Biol. Chem. 267 (1992) 59645967.

[21] J.C. Fernandez-Maculet, J.G. Dong, S.F. Yang, Activation of 1-aminocyclopropane-1-carboxylate oxidase by carbon dioxide, Biochem. Biophys. Res. Commun. 193 (1993) 1168-1173.

[22] J.J. Smith, Z. Zhang, C.J. Schofield, P. John, J.E. Baldwin, Inactivation of 1-aminocyclopropape-1-carboxylate (ACC) oxidase, J. Exp. Bot. 45 (1994) $521-527$.

[23] B. Vioque, J.M. Castellano, In vivo and in vitro 1-aminocyclopropane1 -carboxylic acid oxidase activity in pear fruit: role of ascorbate and inactivation during catalysis, J. Agric. Food Chem. 46 (1998) 1706-1711.

[24] Z. Zhang, C.J. Schofield, J.E. Baldwin, P. Thomas, P. John, Expression, purification, and characterization of 1-aminocyclopropane-1-carboxylate oxidase from tomato in Escherichia coli, Biochem. J. 307 (1995) 77-85.

[25] L. Brisson, N. El Bakkali-Taheri, M. Giorgi, A. Fadel, J. Kaizer, M. Reglier, T. Tron, E.H. Ajandouz, A.J. Simaan, 1-Aminocyclopropane-1-carboxylic acid oxidase: insight into cofactor binding from experimental and theoretical studies, J. Biol. Inorg. Chem. 17 (2012) 939-949.

[26] C.L. Ladner, J. Yang, R.J. Turner, R.A. Edwards, Visible fluorescent detection of proteins in polyacrylamide gels without staining, Anal. Biochem. 326 (2004) $13-20$.

[27] D.J. Hennessy, G.R. Reid, F.E. Smith, S.L. Thompson, Ferene-a new spectrophotometric reagent for iron, Can. J. Chem. 62 (1984) 721-724.

[28] R.C. Driesener, M.R. Challand, S.E. McGlynn, E.M. Shepard, E.S. Boyd, J.B. Broderick, J.W. Peters, P.L. Roach, [FeFe]-hydrogenase cyanide ligands derived from S-adenosylmethionine-dependent cleavage of tyrosine, Angew. Chem. Int. Ed. Engl. 49 (2010) 1687-1690.

[29] R.G. Carlson, K. Srinivasachar, R.S. Givens, B.K. Matuszewski, New derivatizing agents for amino acids and peptides: 1. Facile synthesis of $\mathrm{N}$-substituted 1-cyanobenz[f]isoindoles and their spectroscopic properties, J. Org. Chem. 51 (1986) 3978-3983.

[30] J. Thrower, L.M. Mirica, K.P. McCusker, J.P. Klinman, Mechanistic investigations of 1-aminocyclopropane 1-carboxylic acid oxidase with alternate cyclic and acyclic substrates, Biochemistry 45 (2006) 13108-13117.

[31] A.H. Rosenberg, B.N. Lade, C. Dao-shan, S.W. Lin, J.J. Dunn, F.W. Studier, Vectors for selective expression of cloned DNAs by T7 RNA polymerase, Gene 56 (1987) 125-135.

[32] D. Lanneluc-Sanson, C.T. Phan, R.L. Granger, Analysis by reverse-phase highpressure liquid chromatography of phenylisothiocyanate-derivatized 1-aminocyclopropane-1-carboxylic acid in apple extracts, Anal. Biochem. 155 (1986) 322-327.

[33] F.B. Abeles, P.W. Morgan, M.E. Saltveit Jr., Ethylene analysis and properties of the gas, in: Ethylene in Plant Biology, Academic Press, San Diego, 1992, pp $14-55$.

[34] T.M. Ward, M. Wright, J.A. Roberts, R. Self, D.J. Osborne, Analytical procedures for the assay and identification of ethylene, in: J.R. Hillman (Ed.), Isolation of Plant Growth Substances, Cambridge University Press, Cambridge, UK, 1978 pp. 135-151.

[35] M.V. Miniaev, M.B. Belyakova, N.V. Kostiuk, D.V. Leshchenko, T.A. Fedotova, Non-obvious problems in Clark electrode application at elevated temperature and ways of their elimination, J. Anal. Methods Chem. 2013 (2013) 249752.

[36] M.E. LeFevre, H.R. Wyssbrod, W.A. Brodsky, Problems in the measurement of tissue respiration with the oxygen electrode, Bioscience 20 (1970) 761-764.

[37] G.R. Buettner, B.A. Jurkiewicz, Catalytic metals, ascorbate, and free radicals: combinations to avoid, Radiat. Res. 145 (1996) 532-541.

[38] M.J. Burkitt, B.C. Gilbert, Model studies of the iron-catalysed Haber-Weiss cycle and the ascorbate-driven Fenton reaction, Free Radic. Res. Commun. 10 (1990) 265-280.

[39] W.H. Koppenol, The Haber-Weiss cycle-70 years later, Redox Rep. 6 (2001) 229-234.

[40] S. Kurniawati, J.A. Nicell, A pseudo-steady state model of the kinetics of laccase-catalyzed oxidation of aqueous phenol, J. Chem. Technol. Biotechnol 81 (2006) 1198-1208

[41] L.A. del Río, M.G. Ortega, A.L. López, J.L. Gorgé, A more sensitive modification of the catalase assay with the Clark oxygen electrode: application to the kinetic study of the pea leaf enzyme, Anal. Biochem. 80 (1977) 409-415.

[42] P. De Montigny, J.F. Stobaugh, R.S. Givens, R.G. Carlson, K. Srinivasachar, L.A. Sternson, T. Higuchi, Naphthalene-2,3-dicarboxyaldehyde/cyanide ion: a rationally designed fluorogenic reagent for primary amines, Anal. Chem. 59 (1987) 1096-1101.

[43] A. Sano, M. Takezawa, S. Takitani, Fluorometric determination of cyanide with 2,3-naphthalenedialdehyde and taurine, Talanta 34 (1987) 743-744.

[44] B.K. Matuszewski, R.S. Givens, K. Srinivasachar, R.G. Carlson, T. Higuchi, $\mathrm{N}$-substituted 1-cyanobenz[f]isoindole: evaluation of fluorescence efficiencies of a new fluorogenic label for primary amines and amino acids, Anal. Chem. 59 (1987) 1102-1105.

[45] D.E. Barnes, P.J. Wright, S.M. Graham, E.A. Jones-Watson, Techniques for the determination of cyanide in a process environment: a review, Geostand. Newsl. 24 (2000) 183-195.

[46] P. Kaur, D. Sareen, S. Kaur, K. Singh, An efficacious "naked-eye" selective sensing of cyanide from aqueous solutions using a triarylmethane leuconitrile, Inorg. Chem. Commun. 12 (2009) 272-275.

[47] J.G. Dong, J.C. Fernandez-Maculet, S.F. Yang, Purification and characterization of 1-aminocyclopropane-1-carboxylate oxidase from apple fruit, Proc. Natl Acad. Sci. U.S.A. 89 (1992) 9789-9793. 